\title{
PERFIL EPIDEMIOLÓCICO E SOCIAL DA FIBROSE CÍSTICA NA INFÂNCIA E ADOLESCÊNCIA
}

\author{
EPIDEMIOLOGICAL AND SOCIAL PROFILE OF CYSTIC \\ FIBROSIS IN CHILDHOOD AND ADOLESCENCE
}

\author{
Sueli Maria dos Reis Santos', Mayara Dias Barroso², \\ Thaís Rothier Duarte ${ }^{2}$, Maria Cristina Pinto de Jesus ${ }^{3}$
}

\section{RESUMO}

Objetivo: verificar o perfil epidemiológico e social da Fibrose Cística na infância e adolescência. Metodologia: estudo exploratório, descritivo, com abordagem qualitativa. Participaram 26 crianças e adolescentes com Fibrose Cística e seus responsáveis. Coletaram-se os dados utilizando um formulário e entrevista semiestruturada gravada em áudio. Para análise utilizou-se estatística descritiva e técnica de análise temática de conteúdo. Resultados: 34,6\% idade entre 10 e 14 anos; 69,2\% sexo masculino; $65,3 \%$ cor da pele branca; maioria morava em perímetro urbano; todos com idade superior a três anos frequentavam escola; 46,2\% não tinham irmãos; 92,4\% professavam alguma religião; 38,4\% renda de um salário mínimo; 38,4\% várias hospitalizações. Conclusão: doença precisa ser melhor divulgada. Para cuidar e conviver com a enfermidade a família apóia na espiritualidade para sustentar a esperança. A proporção de adultos com Fibrose Cística cresce progressivamente, gerando novas demandas para os serviços de saúde.

Descritores: Fibrose Cística; Infância; Adolescência; Enfermagem.

\begin{abstract}
Objective: Verify the epidemiological and social profile of the Cystic Fibrosis in childhood and adolescence. Methodology: Exploratory and descriptive study, with a quantitative and qualitative approach. The participants were 26 children and adolescents with Cystic Fibrosis and their caregivers. The data was collected using a form and a semistructured interview recorded in audio. They were statistically analyzed, arranged in table and graph and interviews were submitted to a thematic analysis technique of content. Results: Predominant age between 10 and 14 years; $69.2 \%$ male; $65.3 \%$ white skin color; Most lived in urban area; all above three years old were attending school; $46.2 \%$ had no brothers; $92.4 \%$ professed some religion; $38.4 \%$ income of a minimum wage; $38.4 \%$ several hospitalizations. Conclusion: disease needs to be better publicized. To care for and live with the illness, the family supports their spirituality to sustain hope. The proportion of adults with Cystic Fibrosis grows progressively, generating new demands for health services.
\end{abstract}

Descriptors: Cystic Fibrosis; Childhood; Adolescence; Nursing.

${ }^{1}$ Doutora em Comunicação pela Universidade Federal do Rio de Janeiro (UFRJ), Rio de Janeiro, RJ, Brasil.

2 Enfermeira pela Universidade Federal de Juiz de Fora (UFJF), Juiz de Fora, MG, Brasil.

${ }^{3}$ Doutora em Enfermagem pela Universidade de São Paulo (USP), São Paulo, SP, Brasil. 


\section{Introdução}

A Fibrose Cística (FC) foi reconhecida nos últimos 70 anos como a doença hereditária mais importante e potencialmente letal. É uma enfermidade com acometimento multissistêmico que afeta as glândulas exócrinas e pode ocorrer em diversas células epiteliais, incluindo ductos de suor e pancreáticos, vias aéreas e biliares, intestino e vasos deferentes ${ }^{1}$. Devido à característica genética da FC, com o reconhecimento de mais de mil mutações até o momento, são diversas as manifestações clínicas, dentre elas as principais são a afecção sinopulmonar crônica e a insuficiência pancreática exócrina ${ }^{2-3}$.

Uma das mutações é causada no gene cystic fibrosis transmembrane conductance regulator (CFTR), localizado no braço longo do cromossomo 7 locus q31. A alteração genética mais relatada é a delta F508, descrita pela supressão de três nucleotídeos inseridos na região do códon 508, levando à ausência do resíduo de fenilalanina e um defeito intracelular no mecanismo de processamento da proteína de 1.480 aminoácidos codificada pelo gene CFTR'

A Organização Mundial de Saúde (1971) recomendou as seguintes ações nos serviços de atendimento aos fibrocísticos dos países em desenvolvimento: triagem neonatal para determinar a incidência e identificar os recémnascidos afetados; implementação dos laboratórios para identificar as mutações da FC; desenvolvimento de centros de diagnóstico e de tratamento com equipe multidisciplinar; estabelecimento de uma organização nacional envolvendo familiares, amigos dos fibrocísticos e outros voluntários; estabelecimento de um registro nacional; divulgação sobre esta condição para profissionais de saúde, autoridades públicas e população geral e aumento da colaboração entre os grupos e outras organizações, incluindo a indústria farmacêutica ${ }^{4}$.

Em 2001, com a reavaliação da Triagem Neonatal no Sistema Único de Saúde (SUS), ocorre a publicação da Portaria GM/MS n. ${ }^{0}$ 822, de 6 de junho de 2001, criando o Programa Nacional de Triagem Neonatal (PNTN). Dentre os objetivos deste, destaca-se a ampliação do leque de patologias triadas, dentre elas a FC. O PNTN determina que a triagem envolva a realização do exame laboratorial, a busca ativa dos casos suspeitos, a confirmação diagnóstica, 0 tratamento e o acompanhamento multidisciplinar especializado das crianças. Assim, passa-se a atuar na prevenção e na redução da morbimortalidade provocada pelas patologias triadas 5 .

A suspeição da FC ocorre devido à clínica da doença e aos sinais e sintomas que podem ocorrer nas primeiras semanas de vida. A criança apresenta má absorção, infecções respiratórias recorrentes, suor salgado e ocorrência de íleo meconial. Após o diagnóstico, o tratamento é complexo e demanda rotina exigindo cuidados específicos, a exemplo de manter os pulmões limpos para redução do risco de infecções pulmonares (aerossóis e fisioterapia respiratória), ingestão adequada de líquidos e manutenção de um bom estado nutricional (suplementação de nutrientes e enzimas pancreáticas). Quando há infecção em vigência, antibióticos são necessários, requerendo muitas vezes a hospitalização do paciente ${ }^{3}$. Para que a terapêutica e a minimização dos danos ao organismo sejam realizados efetivamente, é preciso a compreensão da doença e do seu tratamento ${ }^{6}$.

Nos Estados Unidos, a incidência da doença é variável: na etnia branca, vai de 1: 1.200 a 1: 10.000 nascidos vivos, sendo, na raça negra, 1: 17.000 e 1: 90.000 em mongóis. No sexo masculino, sua incidência é maior que no feminino e a sobrevida mais longa. A expectativa de vida para um recém-nascido com fibrose cística é de 40 anos $^{6}$.

Estudo aponta que, no Brasil, a incidência da FC tem sido estimada em 1:7.000 nascimentos, com variações regionais de acordo com a miscigenação local. Segundo o Grupo Brasileiro de Estudos de Fibrose Cística nos anos de 2009 a 2011, foram registrados $859(47,8 \%)$ casos de FC na região Sudeste, $464(25,7 \%)$ no Sul, $380(21,1 \%)$ no Nordeste, 63 (3,5 \%) no Norte e 20 casos (1,1\%) no Centro-Oeste. Em 2014, observou-se uma redução da proporção de casos da região Sul e Sudeste e aumento na proporção de casos registrados no Centro Oeste, Norte e Nordeste ${ }^{7}$.

Por outro lado, estimar a prevalência da FC é difícil por várias razões, dentre estas, destacam-se o elevado número de mutações, a alta taxa de miscigenação, que tem como consequência a heterogeneidade alélica do gene CFTR, sendo a frequência das mutações variável entre os estados da federação. Destaca-se, também, que a heterogeneidade clínica contribui para dificuldade diagnóstica, podendo haver retardo ou não diagnóstico da doença, culminando com a morte precoce de pacientes. Outro fato importante é a limitação de testes diagnósticos, como a triagem neonatal que ainda não é abrangente em todo o território nacional. Esses fatores, associados à falta de estudos epidemiológicos, fazem com que a FC seja ainda uma doença subdiagnosticada ${ }^{8}$.

Convivendo com crianças e adolescentes com FC, acompanhados na atenção secundária e terciária de saúde, em uma instituição de ensino e assistência aos usuários do SUS, em um município de médio porte do Estado de Minas 
Gerais, verificou-se o espaço de atuação do enfermeiro, cujo conhecimento sobre o perfil epidemiológico e social da FC pode contribuir no atendimento e prestação de cuidados a esta clientela e a sua família.

Tomando por base a contextualização acerca das implicações da FC na vida da pessoa, o presente estudo teve como objetivo verificar o perfil epidemiológico e social da FC na infância e na adolescência.

\section{Metodologia}

Trata-se de um estudo exploratório, descritivo, com abordagem qualitativa, realizado no Centro de Tratamento em Fibrose Cística de um hospital de ensino, vinculado ao SUS, referência para os residentes nos estados de Minas Gerais e Rio de Janeiro.

Foram incluídos no estudo crianças e adolescentes com diagnóstico confirmado de FC e o responsável, residente no mesmo domicílio. A definição da faixa etária para classificação da criança ou adolescente pautou-se no Estatuto da Criança e do Adolescente, Art. $2^{\circ}$ : Considera-se criança, para os efeitos desta Lei, a pessoa até doze anos de idade, incompleto, e adolescente aquela entre doze e dezoito anos de idade 9 .

Coletaram-se os dados com responsáveis por 26 crianças e adolescentes cadastradas e acompanhadas no centro de tratamento, no período de abril a julho de 2016. As informações referentes aos aspectos epidemiológicos foram coletadas preenchendo o formulário com iniciais do nome, idade, sexo, cor da pele, escolaridade, número de irmãos, religião, renda familiar, naturalidade, domicílio, local moradia, número de internações, comorbidades. As informações sobre os aspectos sociais relacionados à FC, como o tempo e o local de diagnóstico, adesão ao tratamento e como conviver com a enfermidade, foram coletadas por meio de entrevista semiestruturada, gravada em áudio, com responsáveis das crianças e adolescentes, tendo como questão norteadora: Como é conviver e enfrentar o tratamento da FC?

Em atendimento à Resolução ${ }^{0}$ 466/2012 do Conselho Nacional de Saúde, o Projeto foi aprovado no Comitê de Ética em Pesquisa com Humanos, Parecer n 1.459.551, CAAE 53571316.8.0000.5147 e os dados foram coletados com aquiescência dos entrevistados, após a assinatura do termo de consentimento livre e esclarecido ${ }^{10}$.

A delimitação do número de entrevistados foi definida na $17^{\mathrm{a}}$ entrevista a partir da redundância nas falas e que foram suficientes para desvelar o fenômeno investigado.

As informações obtidas foram digitadas em um banco de dados eletrônico no Microsoft Excel, inicialmente submetidas a uma análise exploratória dos dados. Conforme a variável, apresentou-se a tabela de frequências (variáveis categóricas ou numéricas que foram categorizadas) ou a estatística descritiva. Os resultados dessas análises foram organizados em tabela e gráficos.

As entrevistas foram analisadas utilizando a técnica de análise temática de conteúdo. A partir da transcrição integral das mesmas e leitura exaustiva do material empírico, os fragmentos dos depoimentos foram selecionados, agrupados em conformidade com a semelhança dos relatos e posteriormente apreendendo as ideias relevantes ${ }^{11}$.

Para garantir o sigilo das informações e o anonimato dos participantes da pesquisa, as entrevistas foram identificadas pela letra "F" seguida de um número em ordem crescente de um a 17 (F1, F2... F17).

\section{Resultados e discussão}

O presente estudo ao investigar os aspectos epidemiológicos da FC procurou identificar os fatores que determinam a frequência e a distribuição da FC no coletivo de crianças e de adolescentes. Para aprofundar a verificação dos aspectos sociais buscou-se desvelar o fenômeno do conviver e enfrentar o tratamento da doença na visão de responsáveis por pacientes acompanhados no Centro de Tratamento em Fibrose Cística. Assim, o método qualitativo utilizado além de apropriado ao objeto da investigação, ofereceu elementos teóricos para a análise e operacionalmente foi exequível ${ }^{12}$.

Foram estudados 16 crianças e dez adolescentes com diagnóstico de FC, com idade entre quatro meses e 17 anos e 8 meses. A maioria é natural de Juiz de Fora 10(38,4\%), a seguir Ubá com três (11,5\%) pessoas. Ainda quanto às características epidemiológicas gerais, observou-se que a maior parte $12(46,1 \%)$ morava em perímetro urbano, em bairros periféricos de Juiz de Fora. As crianças com idade superior a três anos frequentavam escola e um adolescente de 17 anos concluiu o ensino médio. Quanto ao número de irmãos, 12(46,2\%) não os tinham e 14(53,8\%) o número de irmãos variava de um a quatro. Observou-se que $24(92,4 \%)$ professavam alguma religião, católica $15(57,6 \%)$ e 
evangélica sete (26,9\%). A renda familiar de 16(61,5\%) participantes foi entre dois e cinco salários mínimos. Do total de participantes, sete $(26,9 \%)$ percebiam benefício da Lei Orçamentária de Assistência Social - LOAS.

Tabela 1 - Distribuição dos 26 crianças e adolescentes com Fibrose Cística, segundo os aspectos epidemiológicos gerais. Juiz de Fora - MC 2016.

\begin{tabular}{|c|c|c|c|c|c|}
\hline $\begin{array}{l}\text { Aspectos } \\
\text { Epidemiológicos }\end{array}$ & $\mathrm{N}=\mathbf{2 6}$ & $\%$ & $\begin{array}{c}\text { Aspectos } \\
\text { Epidemiológicos }\end{array}$ & $\mathbf{N}=\mathbf{2 6}$ & $\%$ \\
\hline Natural & & & Domicílio & & \\
\hline Astolfo Dutra & 01 & 3,8 & Astolfo Dutra & 02 & 7,6 \\
\hline Barbacena & 02 & 7,6 & Barbacena & 02 & 7,6 \\
\hline Carangola & 01 & 3,8 & Carangola & 01 & 3,8 \\
\hline Juiz de Fora & 10 & 38,4 & Juiz de Fora & 12 & 46,1 \\
\hline Leopoldina & 01 & 3,8 & Leopoldina & 02 & 7,6 \\
\hline Matias Barbosa & 01 & 3,8 & Matias Barbosa & 01 & 3,8 \\
\hline Três Rios & 01 & 3,8 & Três Rios & 01 & 3,8 \\
\hline Ubá & 03 & 11,5 & Ubá & 01 & 3,8 \\
\hline Volta Grande & 01 & 3,8 & Volta Grande & 01 & 3,8 \\
\hline Santos Dumont & 01 & 3,8 & Piraúba & 01 & 3,8 \\
\hline Portugal & 01 & 3,8 & Fervedouro & 01 & 3,8 \\
\hline Cataguases & 01 & 3,8 & Piau & 01 & 3,8 \\
\hline Muriaé & 01 & 3,8 & & & \\
\hline Petrópolis & 01 & 3,8 & & & \\
\hline Escolaridade & & & Número de Irmãos & & \\
\hline Não frequentam & & & Nenhum & 12 & 46,1 \\
\hline Pré-escola & 02 & 7,6 & $1-2$ & 07 & 26,9 \\
\hline Ensino Básico & 05 & 19,2 & $3-4$ & 07 & 26,9 \\
\hline $1^{\circ}$ ano & 02 & 7,6 & & & \\
\hline $2^{\circ}$ ano & 02 & 7,6 & Religião & & \\
\hline $3^{\circ}$ ano & 02 & 7,6 & Não têm & 02 & 7,6 \\
\hline $4^{\circ}$ ano & 00 & 00 & Católica & 15 & 57,6 \\
\hline $5^{\circ}$ ano & 02 & 7,6 & Evangélica & 07 & 26,9 \\
\hline $6^{\circ}$ ano & 05 & 19,2 & Espírita & 02 & 7,6 \\
\hline $7^{\circ}$ ano & 02 & 7,6 & & & \\
\hline $8^{\circ}$ ano & 01 & 3,8 & Renda Familiar & & \\
\hline $9^{\circ}$ ano & 01 & 3,8 & Até 1 salário & 10 & 38,4 \\
\hline Ensino Médio & 02 & 7,6 & 2 - 5 salários & 16 & 61,5 \\
\hline
\end{tabular}

Fonte: Dados dos pacientes cadastrados no Centro de Tratamento em Fibrose Cística

A expectativa de vida varia de acordo com o grau de desenvolvimento socioeconômico e científico dos pais, condições de tratamento e idade da criança ao diagnóstico ${ }^{13}$. 
Alegislação brasileira, através da Lei $n^{0} 7.713$, de 22 de dezembro de 1988, no inciso XIV do Art. $6^{\circ}$, confere benefícios e direitos especiais aos portadores de doenças graves: portadores de moléstia profissional, tuberculose ativa, alienação mental, esclerose múltipla, neoplasia maligna, cegueira, hanseníase, paralisia irreversível e incapacitante, cardiopatia grave, doença de Parkinson, espondiloartrose anquilosante, nefropatia grave, hepatopatia grave, estados avançados da doença de Paget (osteíte deformante), contaminação por radiação, síndrome da imunodeficiência adquirida ${ }^{14}$.

A LOAS, Lei $n^{0} 8.742$, de 7 de dezembro de 1993, contempla com o benefício às pessoas idosas acima de 65 anos ou ainda pessoas que tenham alguma deficiência que as incapacite para o trabalho e para a própria vida diária, tornando-as dependentes de terceiros. Para fazer jus ao benefício, a renda familiar deve ser de até 1/4 do salário mínimo em vigor, por pessoa do grupo familiar, incluindo o próprio requerente ${ }^{15}$. Em 1995, com a aprovação da Lei $n^{0} 9.250$, de 26 de dezembro de 1995 (Art. 30, $\S 2^{\circ}$ ), foi incluída a doença "fibrose cística - mucoviscidose" no inciso XIV, do art. $6^{\circ}$, da Lei $n^{0} 7.713$, de 22 de dezembro de $1988^{16}$.

Quanto aos sinais e sintomas sugestivos de fibrose cística, dos 26 participantes da pesquisa, seis $(23,1 \%)$ foram acometidos por íleo meconial e um (3,8\%) tinha hérnia inguinal. Foram referidas afecções respiratórias associadas à FC, como rinite, sinusite, pneumonia, bronquite e asma. Em relação a outras doenças associadas à FC, destacam-se dois $(7,7 \%)$ adolescentes com Diabetes mellitus e um (3,9\%) com cardiopatia e transtorno psiquiátrico.

Questionados sobre necessidade de hospitalização, nove $(34,6 \%)$ não experienciaram esse evento, enquanto $10(38,4 \%)$ precisaram ser internados várias vezes (de três a dez internações).

Em um estudo sobre o estigma da fibrose cística, os autores afirmam que esta enfermidade afeta especialmente pessoas de etnia branca e tem como manifestações clínicas disfunção gastrintestinais como diarréia crônica, com fezes volumosas, gordurosas, pálidas, desnutrição crônica, íleo meconial, prolapso retal, insuficiência pancreática, constipação e refluxo gastroesofágico. As disfunções respiratórias pautam-se na infecção crônica de vias aéreas, doença pulmonar obstrutiva crônica progressiva, pneumotórax, hemoptise e pólipos nasais ${ }^{17}$.

Crianças e adolescentes com doença crônica necessitam de internações sistemáticas e frequentes e, para diminuir as incertezas e as tristezas do paciente e de seus familiares, o profissional deve ter o domínio das informações sobre a enfermidade, buscando minimizar erros de conduta no atendimento desta população ${ }^{18}$. A evolução da FC pode ser acidentada por hospitalizações, cirurgias, limitações físicas, dependência de tecnologia e o transplante pulmonar, levando os familiares e os pacientes a conviver com esta condição ${ }^{19}$.

No presente estudo predominou a faixa etária entre 10 e 14 anos, nove (34,6\%). Esses dados convergem com os apresentados no Relatório de 2014 do Grupo Brasileiro de Estudos de Fibrose Cística. De 216 casos de fibrose cística, $75,4 \%$ eram menores de 18 anos. No período de 2009 a 2014, ocorreu uma redução de 6\% nesta faixa etária e um aumento de $5 \%$ nos maiores de 18 anos $^{7}$.

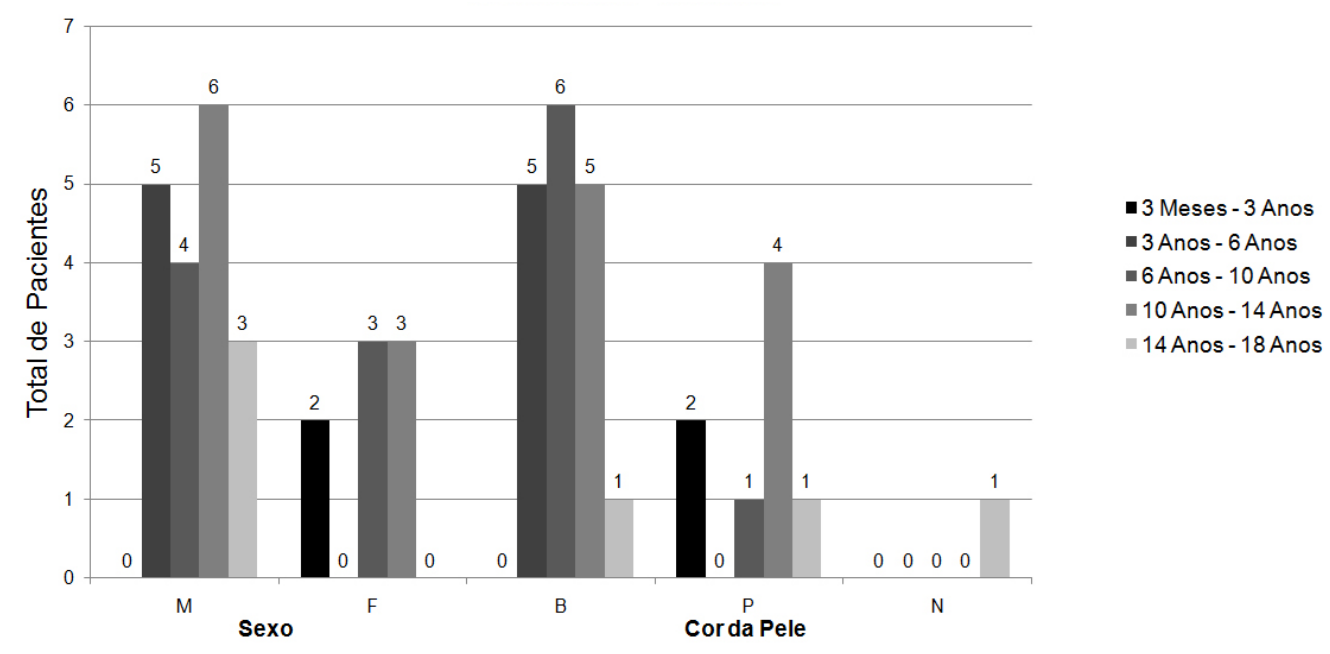

Figura 1 - Distribuição das 26 crianças e adolescentes com Fibrose Cística, segundo os aspectos epidemiológicos gerais: idade, sexo e cor da pele. Juiz de Fora - MC 2016

Fonte: Dados dos pacientes cadastrados no Centro de Tratamento em Fibrose Cística 
Verificou-se que a maioria dos participantes era do sexo masculino 18(69,2\%); a cor da pele, 17(65,3\%) branca, oito $(30,7 \%)$ parda e apenas um de cor negra. Segundo dados do Relatório de 2014 do Grupo Brasileiro de Estudos de Fibrose Cística, considerando o registro de 2924 casos de FC registrados no Brasil, 52,8\% era do sexo masculino e $69,4 \%$ se autodeclararam com pele branca. Estes dados corroboram os achados da presente pesquisa ${ }^{7}$.

Na América Latina, no Uruguai e na Argentina, cerca de $90 \%$ da população e de origem Caucasoide, enquanto no México, Colômbia e Chile, $57 \%$ a $87 \%$ são mestiços (Caucasoides com Ameríndios). Ainda no Uruguai, Equador, Colômbia, Venezuela e Brasil, há afrodescendentes. Devido a mistura étnica, o mapeamento das mutações mostra-se complexo, sendo mais frequente a F508del, principalmente em países com grande contribuição dos Caucasoides na sua composição étnica. Algumas mutações são específicas de determinadas regiões, como na Colômbia e no México, em que, respectivamente, $14 \%$ a $25 \%$ dos alelos CFTR de pacientes fibrocísticos são de mutações raras e únicas destes países. No Brasil, embora a F508del seja a mutação mais comum, sua frequência fica em torno de 47,7\%, sendo menos frequente do que na Europa e nos Estados Unidos ${ }^{20}$.

A suspeição para FC é realizada inicialmente através da triagem neonatal, por meio do teste do pezinho. A dosagem da tripsina imunorreativa (TIR) nos fibrocísticos se encontra elevada até o primeiro mês de vida. Com a repetição do exame, de preferência antes que o neonato atinja $030^{\circ}$ dia de vida, se o resultado indicar alteração nos valores de tripsina, 0 diagnóstico é confirmado ou excluído pelo teste do suor, que é tido como padrão ouro para o diagnóstico da doença ${ }^{21}$.

No presente estudo, $16(61,5 \%)$ de crianças e de adolescentes foram diagnosticados através da triagem neonatal com idade inferior a quatro meses, enquanto seis $(23 \%)$ foram diagnosticados com idade superior a cinco anos por meio do teste do suor.

Evidenciou-se no presente estudo que o tratamento foi iniciado imediatamente após o diagnóstico. Em estudo sobre os aspectos epidemiológicos da fibrose cística, afirma-se que o rastreamento neonatal possibilita o diagnóstico de FC a muitas crianças ainda assintomáticas e, assim, emergem os desafios de abordar a criança e a família com foco no futuro e na promoção de qualidade de vida ${ }^{20}$.

$\mathrm{Na}$ análise temática de conteúdo dos depoimentos de responsáveis por crianças e adolescentes com $\mathrm{FC}$ as falas foram carregadas de opiniões, crenças, valores, representações, relações e ações humanas e sociais na perspectiva dos participantes do estudo frente a uma doença crônica, e, dessa forma, sendo capaz de construir conhecimento novo por contemplar as exigências de um construto científico ${ }^{10}$.

\section{O desconhecimento e pouca divulgação da FC}

Os depoimentos apontaram desconhecimento sobre FC por enfermeiros no atendimento de urgência/emergência, professores na escola e as pessoas de um modo geral que, não entendem ser uma doença infectocontagiosa. Assim expressos:

Maior dificuldade é o atendimento na UPA, os enfermeiros não sabem sobre fibrose cística, se tem 50 pessoas, ela é 51, eu tenho carteirinha de prioridade e eles não a passam na frente. Esse primeiro atendimento é o mais difícil. (F2)

Os professores não conhecem essa doença (F9).

Teve um coleguinha que afastou dele, porque o pai achava que transmitia. (F4)

No estudo sobre narrativas da experiência de pais de crianças com fibrose cística, os autores legitimam que 0 despreparo dos profissionais de saúde acrescenta sofrimento à procura dos familiares por diagnóstico e tratamento, configurando-se, assim, desconhecimento de ações terapêuticas e legais 22.

O resultado do presente estudo sobre o pouco conhecimento e divulgação da FC corrobora os resultados de um sobre as vivências de familiares de crianças e adolescentes com fibrose cística, quando verificaram a necessidade de uma maior divulgação de informações sobre a doença na sociedade e no meio acadêmico. Enfatizam que o desconhecimento sobre a doença, aliado a pouca valorização conferida às informações dos cuidadores, pode prejudicar o acesso das famílias à assistência de suas crianças e adolescentes ${ }^{23}$. 


\section{Adesão ao tratamento da FC e as dificuldades enfrentadas}

O acompanhamento da criança e do adolescente pela equipe multidisciplinar com agendamento regular, dentre outros aspectos, torna-se importante para adesão ao tratamento correto e orientações necessárias. Por se tratar de uma doença que para o trabalho e a própria vida diária, torna o portador da mesma dependente de terceiros, além do benefício assegurado pela Lei n ${ }^{0}$ 8.742, de 7 de dezembro de 1993, as medicações são fornecidas pelo SUS através da Secretária de Saúde do Estado. Porém alguns participantes relataram a dificuldade de enfrentar a falta, o atraso ou até mesmo a troca de remédios na dispensação dos mesmos.

[...] dificuldades das medicações que às vezes atrasa, às vezes fica um mês, dois meses sem vir. A medicação é muito cara, a maioria importada. Nesse aspecto, há dificuldades, esta oscilação, de faltar ou não entregar ou vir medicação errada, trocada e não poder atender a gente. (F2)

Às vezes, não tem remédio onde eu pego [...] Não tenho condições de comprar. Eu queria fazer direitinho de acordo que nutricionista pede, mas não tem como, a renda muito pouca, não tenho condições, não vou mentir. (F9)

A FC é uma doença que compromete vários órgãos e não tem cura, impondo a família a conviver com uma rotina complexa e contínua, exigindo uma atenção integral para administrações de medicamentos e um tratamento que envolve consultas com vários profissionais ${ }^{24}$. difícil. (F11)

A dificuldade maior é a ingestão do sal. Ela chega a fazer vômito. É a parte mais

Ela tem e toma as medicações reclamando. É muito repetitivo as coisas. Então ela fica muito enjoada por causa disso. (F13)

Eu recebo os medicamentos, mas, às vezes, a dieta não consigo fazer. (F14)

Ele não gosta de tomar os remédios, é um sacrifício. Não quer tomar remédio, ir na fisioterapia, não quer vir consultar, chora e chega a dizer: "Prefiro morrer a ficar indo lá e tomando remédio. (F15)

O tratamento para a doença crônica, em destaque a FC, é permanente, e a não adesão ao tratamento pode gerar complicações, podendo ser resolvidas se suas causas forem detectadas. É importante realizar estratégias para se adaptar ao novo estilo de vida, pois gera estresse ao paciente que muda sua rotina, altera sua aparência pessoal e diminui sua força física. Para um planejamento eficiente e eficaz, é necessário avaliar o comportamento de adesão ao tratamento. Quando o atendimento é satisfatório, o cuidado e principalmente o tratamento medicamentoso se tornam melhores, cooperam mais com a intervenção orientada e o índice de não adesão ao tratamento diminui ${ }^{25}$.

\section{Convivendo com a FC apoiada pela crença e pela fé}

A ocorrência da FC na criança ou no adolescente acarreta na família importantes e profundas alterações em sua dinâmica, interferem no cotidiano de todos, impõe sofrimento, angústia e insegurança. Sendo assim, a família carece de atenção, principalmente o cuidador do fibrocístico que precisa de apoio, na fase de descoberta da doença e total acolhimento no momento da crise ${ }^{23}$.

Às vezes acho que acostumei. Eu não coloco na cabeça que ele tem fibrose, eu dou os remédios fingindo que estou dando para dor de barriga, para não ficar com aquilo na cabeça senão eu choro muito. (F9) 
É uma doença que a gente vive um dia de cada vez. Eu não fico me torturando, eu olho mais as conquistas, eu tenho me controlado, eu me agarro mais a isso do que a qualquer desespero ainda. Eu sei que tem uma fase mais complicada lá na frente. Eu estou, no momento, vivendo em paz com fibrose cística. (F8)

A fibrose cística é um tratamento que faz e não resolve [...] é muito difícil conviver com doença crônica. (F13)

Conhecer a doença e meios para assegurar qualidade vida possibilita à família aceitar melhor a condição da criança ou do adolescente, passando a ter mais segurança ao ver outras crianças e adolescentes com o mesmo problema que vivem normalmente. $O$ tempo é aliado à aceitação e assim cada um aprende a lidar com a doença. Lidar no sentido de enfrentar as dificuldades e buscar estratégias necessárias para superação.

Depois vendo outras pessoas, outras crianças tendo uma vida normal, a gente passa a aceitar melhor e entende que tem que fazer o tratamento e que você aceita melhor. (F11)

As famílias precisam ser informadas sobre as perspectivas da FC em relação aos avanços técnicos e científicos, atualmente muitos portadores de FC vivem além dos 50 ou 60 anos, o número de pessoas adultas com a doença tem aumentado. Em duas décadas o número de adultos com FC aumentou mais de $47 \%$ e essa estatística continua a crescer ${ }^{20}$.

Nem sempre os familiares compreendem as informações passadas pelos profissionais em relação à FC. Assim, sentemse assustados diante de um prognóstico que prevê pouco tempo de vida para as crianças/adolescentes e podem experimentar sentimentos de desespero, de medo e de culpa que prevalecem junto às manifestações de não aceitação da realidade ${ }^{23}$.

Em estudo sobre as dificuldades vivenciadas por mães de pessoas com fibrose cística, afirmou-se que, com o conhecimento adquirido sobre a doença, foi possível tomar o controle da situação, abolir o medo e a sensação de impotência, oportunizando a adaptação e enfrentamento do problema com atitudes positivas ${ }^{24}$.

No presente estudo, identificou-se que, ao grupo de sentimentos explicitados, pode-se acrescentar a negação da realidade:

Eu não sinto nada, meu filho é normal. Nós vivemos muito bem com fibrose cística. Se tivesse outro filho, não me importaria que tivesse, pois é uma vida normal. (F12)

O conhecimento dos processos que envolvem a família dos portadores de FC, permite um novo modo de atuação da enfermagem ${ }^{26}$. Isso se aplica aos intensos e diferentes sentimentos experienciados por aqueles que convivem com a doença.

A doença crônica acaba atingindo o viver em uma grande extensão, alterando as relações com a família, com a sociedade, com as instituições de saúde, com os cuidadores e demais grupos, podendo mudar a fé e os princípios pessoais dos que com ela convivem ${ }^{22}$. Neste aspecto, os participantes verbalizaram o sentimento de como é conviver com FC, deste modo:

Hoje, graças a Deus, ela tem mais resistência, não fica tanto tempo internada [...] Graças a Deus, o atendimento que ela tem desde que nasceu até hoje eu posso te afirmar que é melhor do que particular. (F2)

Entreguei na mão de Deus, não conhecia a doença [...] quando ele pergunta: "mãe, eu tenho que tomar remédio o resto da minha vida?" Eu enrolo falando: "Deus vai te curar!" Graças a Deus, ele ganha o remédio, mas às vezes falta. (F9)

Devido à evolução da FC, que pode exigir hospitalização, intervenção cirúrgica, limitação física, dependência tecnológica e até do transplante pulmonar, os familiares e pacientes lidam no cotidiano com a vida e morte a todo instante. De modo racional ou não, isso se dá desde o momento do diagnóstico ${ }^{19}$. Implícita ou explicitamente, é possível entender que a morte se apresenta no imaginário dos familiares como figura dramática devido à cronicidade da FC. Como mencionou uma mãe:

Vamos vivendo! Deixa a vida rolar até onde Deus quiser. Eu vou lutar por ele, só tenho ele. (F4) 
0 presente estudo, em relação à crença e à fé verbalizada pelos familiares, apresenta um resultado similar de um estudo onde os autores certificaram de que crianças e adolescentes renais crônicos por de falas e gestos que expressavam emoção, esperança e crença em um Ser superior, o que demonstrava a fé em Deus ${ }^{27}$.

A esperança na recuperação da doença da criança é um suporte que mantém a família fortalecida emocionalmente. A espiritualidade e a fé se tornam presentes na vida das pessoas que procuram confiança e sentido em um ser superior frente a complexidade das situações a serem enfrentadas. $O$ fortalecimento para aceitar a doença, o tratamento e as recaídas originam-se da luta, da fé e da esperança. Os familiares depositam sua fé em Deus, como mais uma forma de apoio, utilizando de suas práticas de invocação para minorar a dor causada pela doença na criança e sofrimento de todos, que se transforma em mais um suporte do cuidado. A expectativa de cura encontra consolo na fé18.

A sobrevida dos pacientes portadores de FC vem aumentando significativamente com os avanços tecnológicos e científicos. As melhores abordagens no tratamento da doença pulmonar e do estado nutricional desses pacientes emergem como responsáveis por essas mudanças. Os adultos provavelmente terão que enfrentar complicações como diabetes específico da doença e osteoporose, bem como demandar necessidade de abordagem sobre transtornos como fertilidade e transplante pulmonar. Desse modo, há necessidade de programas de cuidados à saúde específicos para a população de adultos com $\mathrm{FC}^{28}$.

Como o estudo foi realizado em um contexto singular, abrangendo um grupo de crianças e adolescentes com suas famílias, acompanhados em um serviço de referência para tratamento de FC, em um município de médio porte de Minas Gerais/Brasil, vale salientar a limitação do mesmo, pois, apesar de abranger os aspectos epidemiológicos e os aspectos sociais da FC na infância e adolescência, não é uma realidade absoluta para todos que convivem com situação similar, impedindo generalização dos resultados.

\section{Considerações Finais}

A população com FC tem crescido significativamente a partir do diagnóstico precoce e do reconhecimento de manifestações clínicas como pela triagem neonatal. Quanto mais cedo a criança e o adolescente têm acesso a tratamento e acompanhamento em centros especializados, melhor tende a ser sua sobrevida e maior a chance de se promover qualidade de vida.

Como a FC é uma doença progressiva e multissistêmica, sua ocorrência em algum membro da família acarreta importantes e profundas alterações em sua dinâmica e características, atingindo a todos em seu cotidiano, impondo sofrimento, angústia e insegurança. 0 paciente e seus familiares necessitam de apoio, principalmente na fase de descoberta da doença, bem como de informações adequadas e acolhimento no momento da crise.

Os profissionais de saúde precisam estar sensíveis ao problema, respeitando os valores, as crenças e os sentimentos dos familiares que convivem com a doença. Após o impacto do diagnóstico e o enfrentamento das dificuldades rumo à adesão ao tratamento, a família decide lutar pela criança ou pelo adolescente, persegue apoio na divulgação e nos avanços tecnológicos e científicos sobre a doença, e, principalmente, necessita adquirir forças para continuar lutando. Como identificado neste estudo, para a família suportar o fardo de prestar o cuidado à criança ou ao adolescente com FC e conviver 0 dia a dia de expectativas e esperança emerge a espiritualidade.

A FC ainda precisa ser melhor divulgada, pois há avanços em relação ao tratamento multidisciplinar da doença e à qualidade de vida a serem garantidos às crianças e aos adolescentes. A sobrevida tem aumentado e com isso a proporção de adultos portadores de FC cresce progressivamente, assim novas demandas vêm surgindo para os serviços de saúde.

\section{Referências}

1. Pereira MLS, Kiehl MF, Sanseverino MTV. A genética na fibrose cística. Rev HCPA 2011; 31(2): 160-7

2. Lima CSP, Ortega MM, Marson FAL, Zulli R, Ribeiro AF, Bertuzzo CS. Mutações do gene cystic fibrosis transmembrane conductance regulator e deleções dos genes glutationa S-transferase em pacientes com fibrose cística no Brasil. Jornal Brasileiro de Pneumologia, jan./fev. 2012; 38 (1): 50-6.

3. Pizzignacco TP, Mello DF, Lima RG. A experiência da doença na fibrose cística: caminhos para o cuidado integral. Rev esc enferm USP, jun. 2011; 45(3): 638-44. 
4. Santos GP, Chermikoski DMT, Wittig EO, Riedi CA, Rosário NA. Programa de triagem neonatal para fibrose cística no estado do Paraná: avaliação após 30 meses de sua implantação. J. Pediatr, nov.2016; 81(3): 240-4.

5. Ministério da Saúde (BR). Secretaria de Assistência à Saúde. Coordenação-Geral de Atenção Especializada. Manual de Normas Técnicas e Rotinas Operacionais do Programa Nacional de Triagem Neonatal / Ministério da Saúde, Secretaria de Assistência à Saúde, Coordenação Geral de Atenção Especializada. - Brasília: Ministério da Saúde, 2002.

6. Tarantino AB, editor. Doenças pulmonares. 6. ed. Rio de Janeiro: Guanabara Koogan; 2008.

7. Grupo Brasileiro de Estudos de Fibrose Cística. Registro Brasileiro de Fibrose Cística 2014. [Internet]. 2014. [acesso em 2016 nov. 28]. Disponível em: http://portalgbefc.org.br/wp-content/uploads/2016/11/Registro2014_v09.pdf

8. Motal RL, Souza LE, Rocha PHSA, Vieira MJF, Santos JF, Lage VMGB et al. Estudos genéticos sobre a Fibrose Cística no Brasil: uma revisão sistemática. Rev. Ciênc. Méd. Biol, mai./ago. 2015; 14(2):238-45.

9. Brasil. Lei Federal n 8069, de 13 de julho de 1990. Estatuto da criança e do adolescente: [Internet]. Brasília, DF; 1990. [acesso em 2016 nov. 9]. Disponível em: https://www.planalto.gov.br/ccivil_03/leis/L8069.htm

10. Brasil. Resolução № 446/12 do Conselho Nacional de Saúde. Brasília: Ministério da Saúde: [Internet]. Brasília, DF; 2012. [acesso em 2016 nov. 9]. Disponível em: http://conselho.saude.gov.br/resolucoes/2012/Reso466.pdf

11. Minayo MCS. O desafio do conhecimento: pesquisa qualitativa em saúde. 11. ed. São Paulo: Hucitec; 2012.

12. Minayo MCS, Sanches O. Quantitativo-Qualitativo: Oposição ou complementaridade? Cad. Saúde Públ, jul/set 1993; 9 (3): 239-262.

13. Santos LFM. As representações sociais da fibrose cística em pacientes adultos. Revista do Hospital Universitário Pedro Ernesto UERJ, out./nov. 2011; 10(4): 149-53.

14. Brasil. Lei $n^{0} 7.713$, de 22 de dezembro de 1988. Altera a legislação do imposto de renda e dá outras providências. [Internet]. Brasília, DF; 1988. [acesso em 2016 nov. 9]. Disponível em: https:/www.planalto.gov.br/ccivil_03/leis/L7713.htm 15. Brasil. Lei n 8.742, de dezembro de 1993. Dispõe sobre a organização da Assistência Social e dá outras providências. [Internet]. Brasília, DF;1993. [acesso em 2016 nov. 9]. Disponível em: http://www.planalto.gov.br/ccivil_03/Leis/L8742.htm 16. Brasil. Lei $n^{0} 9.250$, de 26 de dezembro de 1995. Altera a legislação do imposto de renda das pessoas físicas e dá outras providências. [Internet]. Brasília, DF; 1995. [acesso em 2016 nov. 9]. Disponível em: http://www.planalto.gov.br/ ccivil_03/leis/L9250.htm

17. Santos LM, Valois HR, Santos SSBS, Carvalho ESS, Santana RCB, Sampaio SS. Aplicabilidade de modelo teórico a famílias de crianças com doença crônica em cuidados intensivos. Rev Bras Enferm, mar./abr. 2014; 67(2): 187-94.

18. Afonso SBC, Mitre RMA. Notícias difíceis: sentidos atribuídos por familiares de crianças com fibrose cística. Ciênc. saúde colet, set.2013; 18 (9): 2605-13.

19. Firmida MC, Lopes AJ. Aspectos Epidemiológicos da Fibrose Cística. Revista do Hospital Universitário Pedro Ernesto UERJ, out./nov. 2011; 10(4): 12-22.

20. Rosa FR, Dias FG, Nobre LN, Morais HA. Fibrose cística: uma abordagem clínica e nutricional. Rev. Nutr. [Internet]. 2008 Dec [cited 2016 Nov 01]; 21(6): 725-737. Disponível em: http://dx.doi.org/10.1590/S1415-52732008000600011

21. Afonso SBC, Gomes R, Mitre RMA. Narrativas da experiência de pais de crianças com fibrose cística. Interface (Botucatu), set. 2015; 19(55): 1077-1088.

22. Pizzignacco TMP, Mello DF, Lima RAG. Estigma e fibrose cística. Rev. Latino-Am. Enfermagem, jan.ffev. 2010; 18(1): 04 telas.

23. Costa ASM, Britto MCA; Nóbrega SM, Vasconcelos MGL, Lima LS. Vivências de familiares de crianças e adolescentes com fibrose cística. Rev. bras. crescimento desenvolv. hum, ago.2010; 20(2): 217-27.

24. Tavares KO, Carvalho MDB, Pelloso SM. Dificuldades vivenciadas por mães de pessoas com fibrose cística. Texto Contexto Enferm, jun. 2014; 23(2): 294-300.

25. Prezotto KH, Abreu IS. O paciente renal crônico e a adesão ao tratamento hemodialítico. Rev. enferm. UFPE, mar.2014; p.600-605, mar. 2014.

26. Luz GS, Santos SSC, Lunardi VL, Pimentel EDC, Pelloso SM, Carvalho MDB. A intersubjetividade no contexto da família de pessoas com fibrose cística. Rev Bras Enferm, mar./abr. 2012; 65(2): 251-56.

27. Pennafort VPS, Queiroz MVO, Jorge MSB. Crianças e adolescentes renais crônicos em espaço educativo-terapêutico: subsídios para o cuidado cultural de enfermagem. Rev esc enferm USP, out.2012; 46(5): 1057-65.

28. Adde FV. Fibrose cística na clínica pediátrica. Pediatr Mod, jan. 2014; 50(1): 1-11. 


\section{Sueli Maria dos Reis Santos}

Endereço para correspondência - Rua: Ivon José Curi, $n^{\circ} 120$, Bairro: Portal da Torre, CEP: 36037- 467, Juiz de Fora, MG, Brasil.

E-mail: sueli.santos@ufjf.edu.br

Lattes: http://lattes.cnpq.br/2195121975051208

Mayara Dias Barroso - maydias1@live.com

Thaís Rothier Duarte - tatarothierduarte@hotmail.com

Maria Cristina Pinto de Jesus - mariacristina.jesus@ufjf.edu.br

Enviado em 09 de novembro de 2016. Aceito em 10 de abril de 2017. 